\title{
MANUFACTURING AND PERFORMANCE EVALUATION OF AUTOMATIC ORANGE GRADING PROTOTYPE
}

\author{
N. M. Tolba1 R. A. Hegazy2 H. M. H. Sorour 3
}

\section{ABSTRACT}

Manual grading of fruits is a time and labours consuming process and results in inability of proper grading. In addition, the manual grading is not yet economically visible at the processing scale and with large quantities of fruits. Therefore, this research therefore developed and manufactured an automated grading prototype which is able to incorporate flexibility and separate selected orange. However, at the same time move objects automatically to the defined places by the regulation of the integrated load cells sensors, microcontroller and relay switch circuit (RSC) to detect a value range of weight and to drive the grading gates and required movements. The prototype consists of feeding unit and grading unit as two major components. Both components are working together smoothly and in sequence to transfer and sort the received orange fruits by implementing different mechanical and electronic parts through proper frames, transmission and control systems. Feeding unit' main components were; electric motor, transmission systems, feeding hopper, conveyer chain and spoons. Grading unit consists of frame, connecting belt, weight sensing area, gates' open-close control units and distribution gates. The automatic grading prototype was tested and evaluated at Rice Mechanization Center (RMC), Agricultural Mechanization Research Institute, Ministry of Agriculture (Meet El Dyba, Kafrelsheikh governorate) during the period from 2014 to 2016. The performance evaluation was conducted at two distances between spoons on conveyer chain (182 and $364 \mathrm{~mm}$ ), four different surfaces of the belt that connect feeding unit to weight sensing area (wood, cotton, linen and leather), grading with and without infrared control unit and three sensing time (3, 6 and $9 \mathrm{sec})$ for Valencia orange

\footnotetext{
${ }^{1}$ Assistant Researcher, Agric. Eng. Res. Inst., Dokki, Giza.

${ }^{2}$ Associate Professor, Agric. Eng., Dept., Faculty of Agric., Kafrelsheikh University.

${ }^{3}$ Professor and Head Dept. of Agric. Eng., Faculty of Agric., Kafrelsheikh University.
} 
fruits. Physical and mechanical properties were measured and recorded for processed fruits. The results showed that the grading prototype is quite successful for grading Valencia orange. The optimum operational conditions for maximizing the grading efficiency were $182 \mathrm{~mm}$ distance between spoons, 3 sec for sensing the weight and using infrared unit to control the feeding rate. Technical evaluation also showed that the maximum productivity value of the grading prototype was $0.47 \mathrm{Mg} / \mathrm{h}$ for Valencia orange with the optimum operational parameters. The cost of materials and fabrications of such prototype was 10,000 LE and total operational cost of the prototype was $26 \mathrm{LE} / \mathrm{h}$, while, optimum production cost were $55 \mathrm{LE} / \mathrm{Mg}$ for Valencia orange with the optimum operational parameters.

\section{INTRODUCTION}

orting and grading are major processing tasks associated with the production of fresh-market fruit types. High-value fresh agricultural products such as orange must be carefully handled, sorted and graded in order to meet customer demands and quality standards. Grading of fruits is an important operation that affects its acceptance to the consumers in national and international market (Mangraj et al., 2009). Sorting and grading are terms which frequently used interchangeably in the food processing industry. Sorting is a separation based on a single measurable property of raw material units, while grading is the assessment of the overall quality of a food using a number of attributes, and as grading usually upgrades the product (Brennan and Grandison, 2006). Manual grading is widely adopted practice world over for citrus fruits. Manual grading is carried out by trained operators who consider a number of grading factors and separate fruits according to their physical quality parameters by visual examination (Omre and Saxena, 2003). Manual grading is costly and the process is time consuming. It has become increasingly difficult for orange growers to employ enough manual labourers for handling such perishable crop at the proper time. Availability of labour has been inadequate during peak seasons. In recent ten years, operations in grading systems for fruits and vegetables became highly automated with 
mechatronics, and robotics technologies. Machine vision systems weight based systems and near infrared inspection systems have been introduced to many grading facilities with mechanisms for inspecting all sides of fruits and vegetables (Kondo, 2009). Sizing is considerably labourintensive postharvest unit operation. Sizing is necessary, as it fetches higher value، attracts buyers and facilitates packaging designs, beside; it improves handling and brings an overall improvement in the marketing system. The main disadvantage of weight sizers is the relatively long time required to weight each fruit. Even continuous flow scales actually have a weighing cycle of about 1 or $2 \mathrm{~s}$. The length of the weighing cycle is proportional to the accuracy of the scales. Thus, throughput is quite limited if a reasonable weighing accuracy is specified. Another drawback is relatively high cost and considerably more complexity, as compared to dimensional sizer (Peleg، 1985; Jarimopas et al., 2007). The size-based mechanical graders suffers disadvantages of any mechanical system over electronic in term of efficiency and accuracy. Further, the development of size-based electronic optical graders is difficult as it requires individual orientation of fruits to acquire equatorial dimensions (Anon، 2002). Color-based automatic grading system development is quite expensive and complex in nature (Amer Eissa and Abdel Khalik, 2012). Weight-grading is capable of more precise separation than in dimensional-grading and reduces labour cost‘ damage, time and power consumption as also improves efficiency and accuracy (Omre and Saxena, 2003). Weight grading of fruit can reduce packaging and transportation costs, and also provide an optimum packaging configuration (Peleg and Ramraz, 1975). The most commonly used packaging method in the transportation and export of fruits is the telescopic, multi-layer tray carton, which relies on each layer of fruit to support some of the weight of the carton, and the cartons above, in a pallet. Any oversized fruit in a tray will receive more pressure and any undersized fruit will not carry their share of the weight, thereby causing bruising of fruit in the tray. Thus, the weight-based sizing by ensuring individual fruit weight lying within a defined weight range ensures a consistent fruit size. Weight-sizing provides the most consistent sizing within a pack and is also critical to avoid bruising of fruit during storage 
and transportation. It has been reported that the weight of spherical fruits like apple, pear and citrus is proportional to the cube of characteristics dimension (Ryall and Lipton, 1972). Mcrae (1985) showed that the application of electronics to weighing systems has led to the development of high-speed check-weighers and beltweighers. These use load transducers, which can weigh about five objects per second. Gomaa et al. (2006) designed, fabricated, tested and evaluated a locally automatic prototype for grading some fruits and vegetables on weight base (oddly and uniform in shape) such as Cara potato as well as sphere crops such as Navel orange. The automatic control system by means of electronic circuits was utilized for operating the proposed grading prototype and decreasing the consumed time to weight each fruit, he used four feeding chain speeds $(0.14,0.17,0.21$ and $0.24 \mathrm{~m} / \mathrm{s})$, four speeds of weight unit belt $(0.30,0.45,0.60$ and $0.75 \mathrm{~m} / \mathrm{s})$ and two starting weight positions $(0.08$ and $0.125 \mathrm{~m})$. The testing results showed that the best performance of the proposed grading prototype for potato tubers and orange fruits can be achieved with the optimum feeding chain speed $0.14 \mathrm{~m} / \mathrm{s}$, the optimum weight belt speed $0.30 \mathrm{~m} / \mathrm{s}$ and the optimum starting weight position $0.125 \mathrm{~m}$.

Thus, weight is the representative of fruit size, and can be employed for grading. The available graders grade fruits and vegetables according to size, shape and colour. However, none of existing graders commercially available in Egypt grade fruits by weight with using arduino circuits. The automation of weight grading by use of load cell, microcontroller is capable of more precise grading than size grader. Accordingly, this study was undertaken for the development of electronically automated grading prototype on weight basis for orange. The physical and mechanical properties of the Valencia orange fruits have been investigated to determine the main operational and design parameters affecting the performance of the proposed prototype.

\section{MATERIALS AND METHODS}

\subsection{Fabricated grading prototype}

An automatic grading prototype on the weight basis has been constructed and locally developed at the engineering workshop of Rice 
Mechanization Center. The prototype has been developed mainly to grade orange fruits automatically on the weight basis. The prototype is sketched in Fig 1. It consists of a feeding unit and grading unit as two major components. Both components are working together smoothly and in sequence to transfer and sort the received orange by implementing different mechanical and electronic parts through proper frames, transmission and control systems. The prototype allows grading orange into four independent weights and it is considering a significant improvement on pre-existing small scale solutions due to the automatic grading. The prototype has been designed in this manner for easiness of fabricated, to reduce energy consumed and costs, it is a modern style grading and reducing the error rate compared to the other systems of grading machines.

\subsubsection{Feeding unit}

The main function of the feeding unit is to feed the weight and grading unit with single orange fruits at equal times. The feeding unit is consisted of the following main parts:

\section{a. Feeding hopper}

A rectangular feeding hopper was designed fabricated and fixed on the feeding unit frame of the proposed grading. It was made from galvanized steel sheet with a thickness of $1 \mathrm{~mm}$. The hopper dimensions were 300 $\mathrm{mm}$ length, $450 \mathrm{~mm}$ width and up to $670 \mathrm{~mm}$ height. To ensure that a shallow of fruits is presented in front of the feeding spoons (cups), the hopper is divided by means of lateral slider diaphragm to avoid the spoons from passing through a dense layer of fruits. Consequently, reducing the damage, which may occur to the fruit sprouts during the grading operation. The base sides of the hopper sloped gradually at angle value more than the repose angle of $0.663 \mathrm{rad}(38 \mathrm{deg}$.) of the fruits to keep the flow of fruits at continues rate. To avoid the free falling of fruits from the hopper bottom at the outlet chamber, a semi-cylindrical tube with diameter of $100 \mathrm{~mm}$ and height of $200 \mathrm{~mm}$ was joined to the hopper bottom, which is regarded to be more than the distance between two consecutive spoons. 


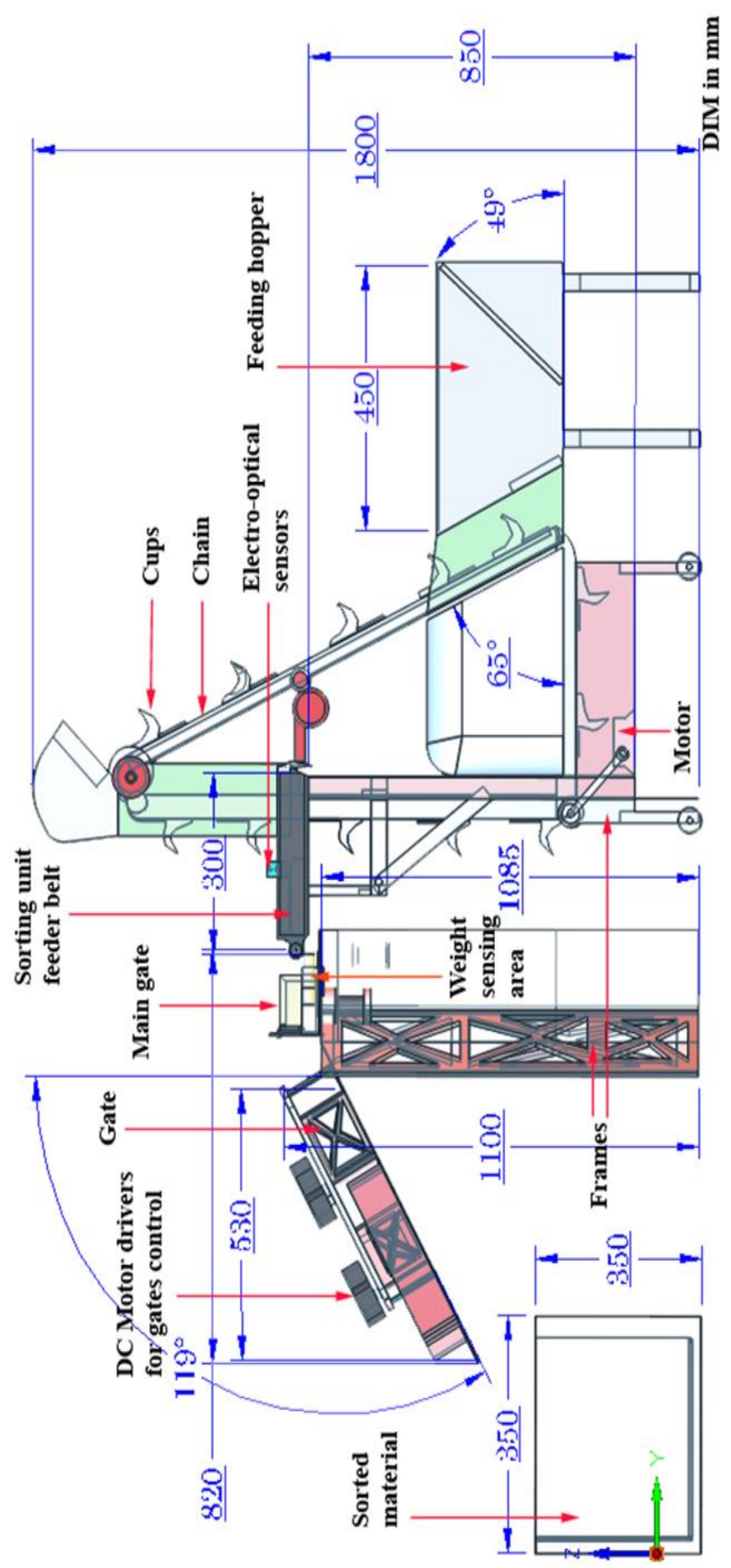

 


\section{b. Conveying chain:}

The conveying chain was made of iron with $3640 \mathrm{~mm}$ length, a set of spoons have been fixed on it and distributed at equal distances $(182 \mathrm{~mm})$ along the chain to pick the fruits from the hopper. This chain is mounted on three supported iron gears.

\section{c. Spoons (cups) of the conveying chain:}

The spoons of the conveying chain have been constructed from aluminum metal. Each spoon has two turgid to pick and carry the single orange fruit from the hopper to the weight and grading unit. The physical and mechanical properties of the graded fruits have been considered at determining the shape and dimensions of the spoons as were $(50 \times 50 \times 85$ $\mathrm{mm}$ ) and to determine the inclined angle of spoons on conveying chain. Each spoon is equipped with two iron steel plates; the first one was fixed on the spoon side connecting with the chain to prevent the spoons from rotating about their axial. The second plate was connected with the first plat at its outer side with inclined angle more than the rolling angle 0.29 $\operatorname{rad}(16.59 \mathrm{deg}$.). The second plate was covered by the rubber to avoid the fruit damage that can happen on it as a result of direction change of the chain motion.

\section{d. Fruits orientor:}

A cuboid orientor, which has been used in the fruits orientation, has been fixed in the upper angle of conveying chain frame. The orientor can bind the fruits between its outer wall and conveying chain at changing the fruit orientation as a result for rotating it. So, the fruit fall from the end of orientor onto grading unit feeder belt.

\section{e. Intermittent motion:}

Feeding unit is a continuous feeding mechanism that is initially receiving the orange and transfers it to the grading unit. To properly feed the orange fruit into the grading system and to prevent the accumulative in sensing area, the feeding unit is being controlled and its motion is determined by an optical sensor. Where, the feeding unit is working only till orange come in contact with the optical sensor that accordingly sends a signal which stops feeding unit motion. The feeding unit starts to work 
again upon receiving a signal due to opening the main releasing gate in the grading unit. Using such mechanism with the feeding unit gives grantee of processing only one orange fruit at the time in weight sensing area of the grading system.

\section{f. Frame}

The feeding unit frame has been constructed from angle steel bars with dimensions of $40 \times 40 \mathrm{~mm}$ and thickness of $3 \mathrm{~mm}$. The conveying chain and hopper were fixed on it. This frame consists of two opposite right triangles, between of them a conveying chain which was fixed on three gears in the triangle vertexes. The conveying chain is driven by means of the gear fixed in the right angle by another chain connecting with the transmission unit. The feeding hopper was fixed on the chord of the right triangle in its down end.

\subsubsection{Weight and grading unit}

The second major part of the prototype is the grading unit which provides weight based grading solution for orange fruits. Grading unit receives orange fruits from feeding unit and sorts them automatically using different sets of sensors, circuits, distributing gates and controllers as shown in Fig 2. The grading unit is consisted of the following main parts:

\section{a. Weight sensing area}

It is the area where the weight information of orange can be detected by load cell. Load cells are integrated sensors that measure weights and output continuous electrical, pneumatic, or hydraulic analog signals and it is generally comprised of three parts: a mechanical system, a strain gauge, and an electronic amplification device. To use the load cell, a bridge of four strain gauges are used to form the load cell with $5 \mathrm{~kg}$ as a maximum reading and $0.1 \mathrm{~g}$ accuracy, which can detect the weight of each orange based on the proportional of the output voltage of the load cell with the different orange weights. This arrangement allows to measure very small changes in the resistance $\Delta R$, which occurs in the strain gauges placed in the arms of the bridge: R1, R2, R3 and R4, considering, $V_{\text {in }}$ the power supply of the bridge or input excitation ( $\mathrm{V}=$ Volts) and $\mathrm{V}_{\text {out }}$ the output signal ( $\mathrm{mV}=$ milivolts). Strain-gauge load cells convert the load acting on them into electrical signals. 

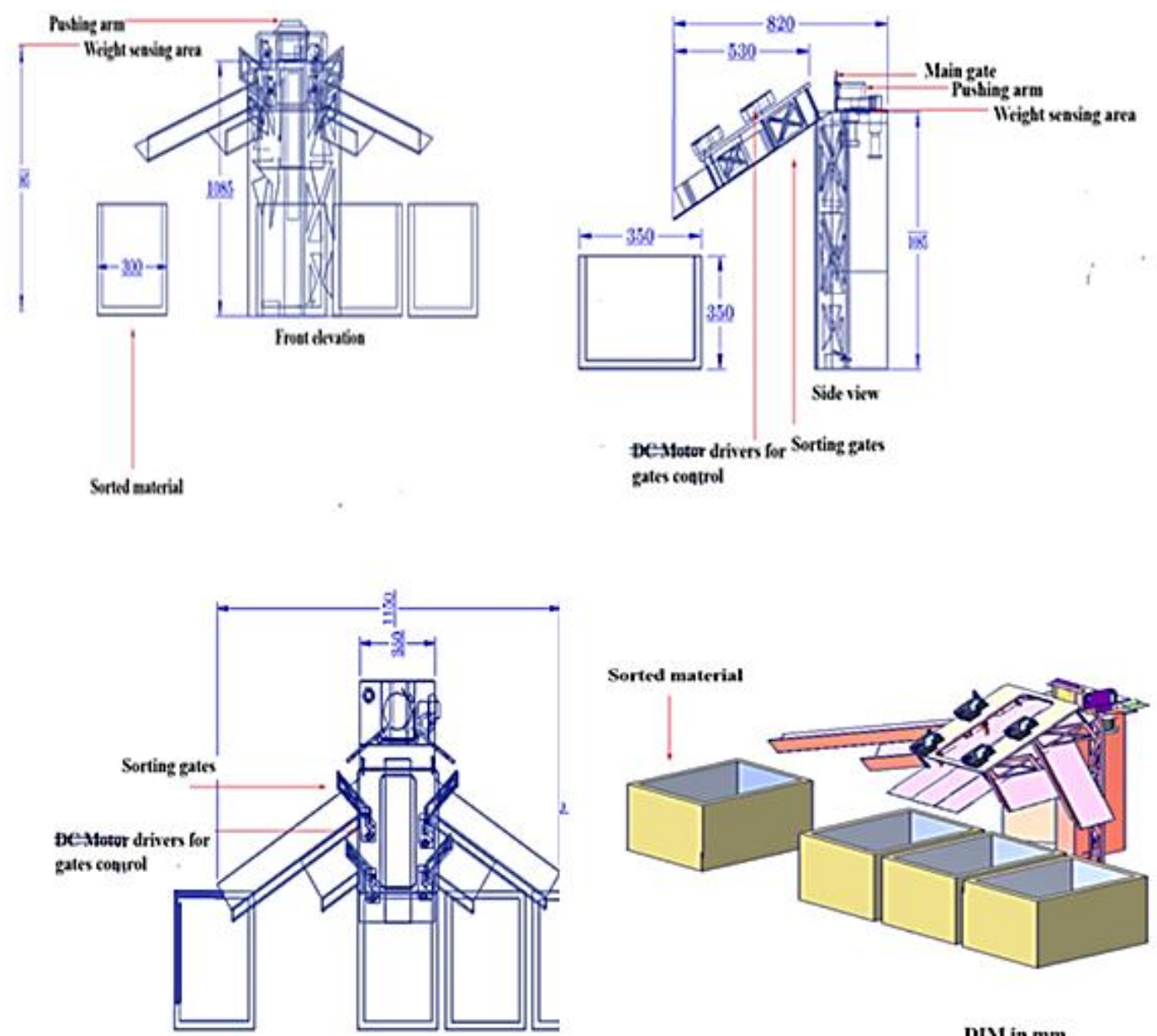

Plan view

DLN in mm

Fig. 2 Sketch for weight and grading unit

The measuring is done with very small resistor patterns called strain gauges - effectively small, flexible circuit boards. The gauges are bonded onto a beam or structural member that deforms when weight is applied, in turn deforming the strain-gauge. As the strain gauge is deformed, it's electrical resistance changes in proportion to the load. Load cell has been chosen to cover all expected weights of the orange with given maximum weight of $5 \mathrm{~kg}$ that can be senses before damage (deformed) to the load cell can happen.

\section{b. Microcontroller}

Output of the load cell is being transferred to a previously programmed microcontroller board (Arduino Mega Board as core microcontroller) . 
Mega is an ATmega2560 as core microcontroller development board itself has 54 groups digital I/O input / output terminal (14 groups do PWM outputs), 16 sets of simulation than the input side, group 4 UARTs (hardware serial ports), using the $16 \mathrm{MHz}$ crystal oscillator. With the bootloader, download the program directly via USB without having to go through other external writer. Supply part of the optional USB power, or as an external power using the AC-to-DC adapter and battery. There are two options for the power supply system of the Mega, USB direct power supply or external power supply. The choice of power supply will be switched automatically. External supply AC-to-DC adapter or the battery can be selected on this control panel. Limit the voltage range of $6 \mathrm{~V}-12 \mathrm{~V}$, but if the voltage supplied is less than $6 \mathrm{~V}$, I / O port may not be supplied to a voltage of $5 \mathrm{~V}$, and therefore instability; if the voltage is greater than $12 \mathrm{~V}$, the regulator device may possibly overheating protection, are more likely to damage the MEGA. Therefore, recommended operating supply id from $6.5-12 \mathrm{~V}$, the recommended power supply is $7.5 \mathrm{~V}$ or $9 \mathrm{~V}$. The processor inside the board is considering brain controlling the machine, it advances the input signal and generates the required actions based on the data that has been calibrated and stored on it.

\section{c. Grading gates and their controllers}

Arduino Mega Board has been calibrated and coded by using C++ programming language, where almost all Arduino libraries are made using it in order to be easily reusable. Calibrating the load cell scale allowed the code to map grammes that the Arduino load cell circuit can achieve and can be seen in the Arduino IDE serial monitor for the weight readings. In this study, four weight categorizes have been determined to be grading on the weight bases and according to the most common weight of available Valencia orange in Egypt; from 80 to 130, from 131 to 181 , from 182 to 232 , and more than $232 \mathrm{~g}$. the amplified strain gauge signal which is converted by the microcontroller, gives an order of opening specific grading gate through DC motors $(24 \mathrm{~V}, 0.1 \mathrm{~A}$ and gearbox 1:30). According to the four weight categories, there are three gates to direct and release three different weights while the fourth category just is being moved forward with closing all the gates. However, 
the machine has the ability to sort five different categorizes, but only four has been used in the study (Fig 3).

DC Motors which control the grading gates are being controlled by Relay Switch Circuit. Relays are electromechanical devices that use an electromagnet to operate a pair of movable contacts from an open position to a closed position. The advantage of relays is that it takes a relatively small amount of power to operate the relay coil, but the relay itself can be used to control motors as in this study. To allow a motor to move in a direction until it hits the required limit and reverse, two relays are enough to achieve the required motion by connecting the $+\mathrm{V}$ motor supply to the $\mathrm{NC}$ connections of two of the relays, and connecting the motor $\mathrm{V}$ supply to the NO connections of those relays. Moreover, connection of the motor should be in between the $\mathrm{C}$ connections of the two relays, and to reverse the motion, the other relay on the motor will run the other way.

\section{d. Weight sensing time and its control unit}

Weight sensing time is being controlled by an infrared control circuit. These circuit was fitted to serve as electronic controller for starting and ending of weight sampling and consists of; ic LM555 which is responsible for time delaying mode of operation and where, the time is precisely controlled by one external resistor and capacitor; optocoupler that respective sensation of fruit entry to the machine; tone decoder for providing a saturated transistor switch when an input signal is present and synchronizing with arduino circuit; and irf230 for connecting the circuit with an electric motor and start-stop operation.

\section{e. Hardware arrangement and platform:}

The circuit's platforms and hardware arrangements have been correlated for proper synchronization between the machine elements and to achieve the required on-time processing. The horizontal feeding chain, which is located just before the sensing area, starts to move with moving the conveyor belt (carrying orange carrier spoons) by an electric motor. Fruits fall from spoons to the feeding chain and reach the infrared control unit located at the end and before the sensing area. 
a
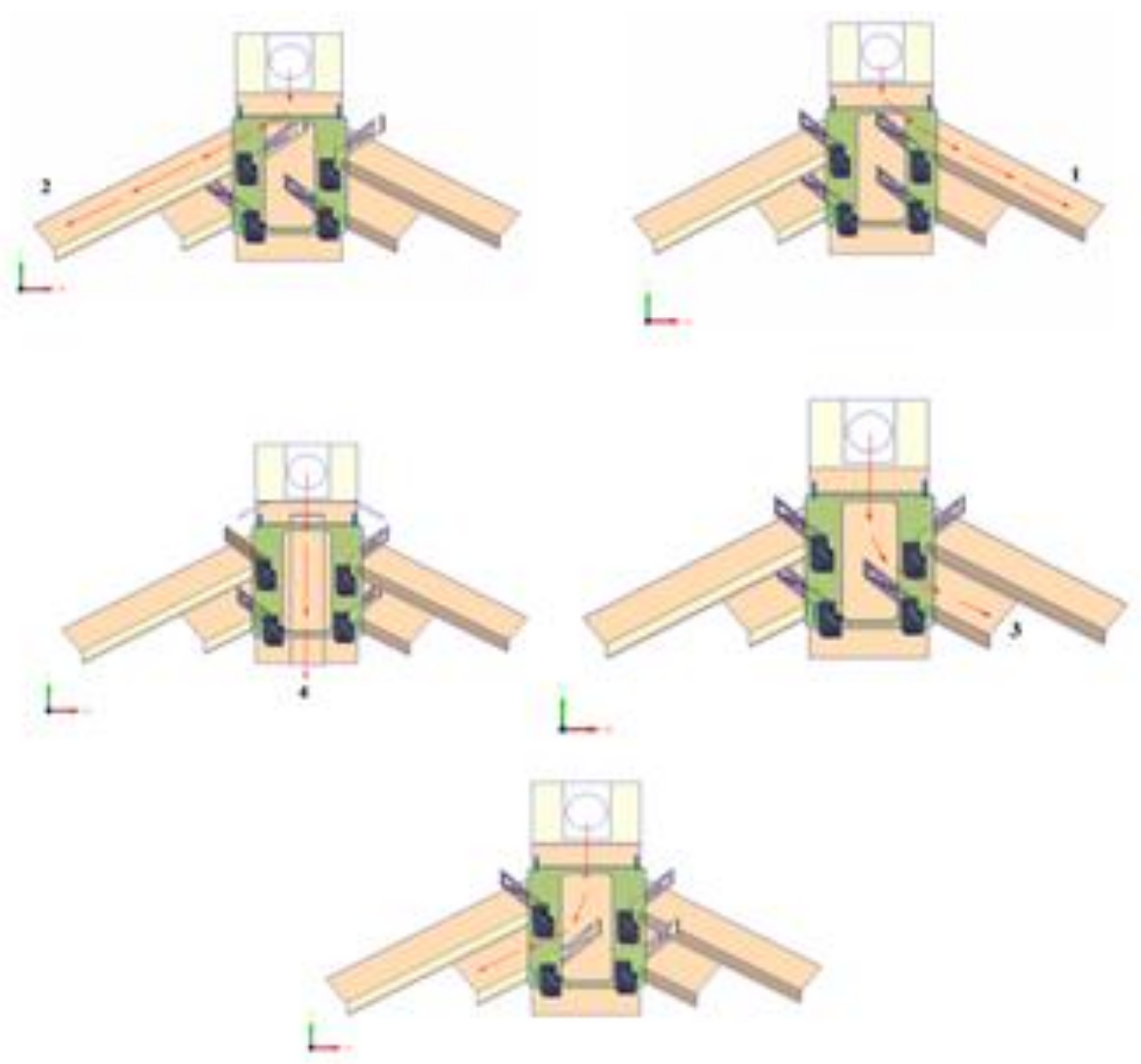

b

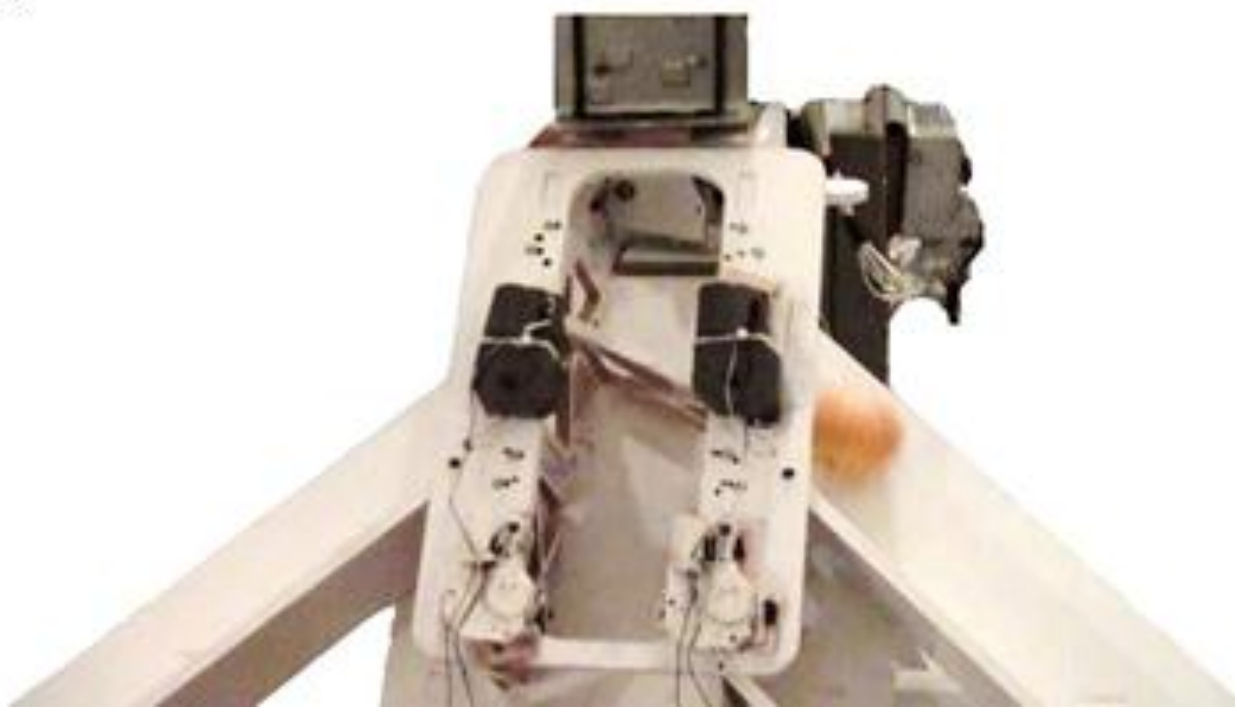

Fig. 3 a: Schematic view and b: photograph of arrangements of grading gates and grading paths 
When infrared circuit is blocked by the orange, feeding chain stop to move and the signal for collection of weight data in specific time is being triggered, the microcontroller starts processing of weight data until subsequent blocking of the infrared circuit. Based on sensing data and data acquired by the microcontroller from the load cell, the arduino circuit controls the selection of opening specific grading gate. When weight sensing time is done the cycle is repeated by operating the electric motor .

\subsection{Methods}

\subsubsection{Physical and mechanical properties of orange}

\subsubsection{Mass of fruit}

One hundred sample for each Valencia orange were randomly selected to determine the average mass of each fruit by using an electronic balance with an accuracy of $0.01 \mathrm{~g}$.

\subsubsection{Volume and orange density}

The actual volume of fruit was measured by using a graduated beaker, its capacity equal one liter. The graduated beaker was filled with water to a defined level, then the fruit was completely immersed in the beaker using glass rod. The actual volume of fruit (V) was calculated based on the different between the two measure volume of water for each fruit. The real density of the fruit was calculated using the following equation:

$$
\mathrm{D}=\frac{\mathrm{M}}{\mathrm{V}}
$$

Where: $\mathrm{D}=$ the real density of the individual fruit, $\mathrm{g} / \mathrm{cm}^{3} ; \mathrm{M}=$ Mass of the individual fruit, $\mathrm{g}$ and $\mathrm{V}=$ Actual volume of the individual fruit, $\mathrm{cm}^{3}$.

\subsubsection{Coefficient of friction}

Coefficients of friction for the Valencia orange have been measured by using four friction surfaces, which were wood, cotton, linen and leather. According to Abd El-Mageed and Abd Alla, 1994 indicated that, the fruits have been placed over the friction surface and the tension force on the fruit surface was gradually increased and stopped when the fruit begin to move. Coefficient of friction has calculated using following equation: 


$$
\mu=\frac{\mathrm{P}}{\mathrm{M}}=\tan \theta
$$

Where: $\mu=$ Coefficient of friction, dimensionless; $\mathrm{P}=$ Force required to start fruit movement on the horizontal plan, $\mathrm{N} ; \mathrm{M}=$ Mass of fruit, $\mathrm{N}$ and $\theta=$ Angle of friction, degree.

\subsubsection{Impact height}

Impact height of orange fruits were accomplished by free fall dropping of each sample from different height ranged from 0.3 to $2 \mathrm{~m}$. The tested sample have been marked and sorted for weeks in room temperature (Amin, 1994). The bruised samples were separated based on the visual inspection of discoloration appeared on the flesh surface of the impacted fruits. On the other hand, the potential energy required for bruising the fruit $(\mathrm{PE})$ has been calculated using the following equation:

$$
\mathrm{PE}=\mathrm{M} \cdot \mathrm{G} \cdot \mathrm{H}
$$

Where: $\mathrm{PE}=$ Potential energy, $\mathrm{j} ; \mathrm{M}=$ Fruit mass, $\mathrm{kg} ; \mathrm{G}=$ Acceleration gravity, $\mathrm{m} / \mathrm{s}^{2}$ and $\mathrm{H}=$ Dropping height, $\mathrm{m}$.

\subsubsection{Rolling angle}

The rolling angle has measured by using an inclined plan with four types of surface wood, cotton, linen and leather. The orange fruits have been placed on the horizontal surface of the inclined plat one by one and then by gradually increasing the angle of inclination, until the fruit begin to roll, and the recorded angle is considered as the rolling angle of the fruit.

\subsubsection{Productivity and efficiency of grading machine}

\subsubsection{Grading productivity}

The productivity and efficiency of grading machine have been determined according to Amin (1994). The grading productivity has been calculated according to the following equation:

$$
\mathrm{C}=\frac{\mathrm{M} \times 60}{\mathrm{~T}_{\mathrm{G}}} \text {. }
$$

Where: $\mathrm{C}=$ Grading productivity of the machine, $\mathrm{Mg} / \mathrm{h} ; \mathrm{M}=$ Mass of classified fruit, $\mathrm{Mg}$ and $\mathrm{T}_{\mathrm{G}}=$ Grading time, min. 


\subsubsection{Grading efficiency:}

The grading efficiency of each outlet has been calculated according to the following equation:

$$
\xi_{\mathrm{i}}=\frac{\mathrm{M}_{1}}{\mathrm{M}} \times 100
$$

Where: $\xi \mathrm{i}=$ Grading efficiency of fruit, $\% ; \mathrm{M}_{\mathrm{I}}=$ Mass of the classified fruits for each outlet, $\mathrm{Mg}$ and $\mathrm{M}=$ Total mass of the fruits for each outlet in the machine, $\mathrm{Mg}$.

The total efficiency of the grading machine has been calculated using the following equation:

$$
\xi=\frac{M_{1}+M_{2}+M_{3}}{M} \times 100
$$

Where:

$\xi=$ Total grading efficiency of the machine, $\% ; \mathrm{M}_{1}+\mathrm{M}_{2}+\mathrm{M}_{3}=$ Masses of the proposed classified fruits for first, second and third outlets, $\mathrm{Mg}$ and $\mathrm{M}=$ Total mass of the fruits for each outlet in the machine, $\mathrm{Mg}$.

\subsubsection{Power and energy requirements for the machine operation}

The consumed power $(\mathrm{kW})$ of the prototype (engine motor, gate motor, arduino and IR control unit has been estimated by using the multi-meter, 700 volt (AC), 10 ampere- (Japanese made) to measure the line current strength and the electric potential. The electric power required for operating the grading machine has been computed by using the following equation:

$$
\mathrm{P}_{\mathrm{el}}=\frac{\mathrm{IE} \times \cos \theta}{1000}
$$

Where: $\mathrm{P}_{\mathrm{el}}=$ The electric power required by the grading machine, $\mathrm{kW}$; $=$ Electric current, Ampere $\mathrm{E}=$ Electric potential, Volt and $\operatorname{Cos} \theta=$ power factor, equal 0.64 .

The energy required by the grading machine in $\mathrm{kWh} / \mathrm{Mg}$ has been calculated by using the following equation:

Energy requirement $=(\mathrm{kW} \cdot \mathrm{h} / \mathrm{Mg})=\mathrm{P}_{\mathrm{el}} / \mathrm{C}$ 
Where: $\mathrm{Pel}=$ Electric power required for grading the fruits, $\mathrm{kW}$ and $\mathrm{C}=$ Grading productivity of the machine, $\mathrm{Mg} / \mathrm{h}$.

Table 1: Specifications of electrical motor, gate's motor, arduino and infrared control unit.

\begin{tabular}{|l|c|c|c|}
\hline \multicolumn{1}{|c|}{ Item } & $\operatorname{Cos} \boldsymbol{\theta}$ & Volt & Ampere \\
\hline Electrical motor ( main motor) & 0.85 & 24 & 3 \\
\hline Gate's motor & 0.8 & 24 & 0.1 \\
\hline Aurduino & & 5 & 0.2 \\
\hline Infrared control unit & & 12 & 0.3 \\
\hline
\end{tabular}

\subsubsection{Cost of grading operation:}

The total cost of grading machine includes charges for ownership and operation. Ownership costs are seemingly independent of use and are often called fixed costs or overhead costs. Fixed costs include depreciation, interest on investment, taxes, housing and insurance. Costs for operation vary directly with the amount of use and are often called variable costs, or operating costs. Variable costs include repair and maintenance, electricity and labour. Grading cost LE/h or LE/ Mg for the proposed grading machine was estimated according to El Khawaga (1999) with the assumptions indicated in Table 2.

\section{Table 2: Assumption for cost of the machine}

\begin{tabular}{|l|l|l|}
\hline No. & Item & Value \\
\hline 1 & Costs of materials and fabrications ( P ), LE & 10000 \\
\hline 2 & Salvage value ( S ), LE & $10 \%$ of ( P ) \\
\hline 3 & Taxes, housing and insurance, LE & $2 \%$ of ( P ) \\
\hline 4 & Interest rate ( i ), LE & 0.15 \\
\hline 5 & Electricity price (E), LE/ kW.h & 0.42 \\
\hline 6 & Machine life (L), year. & 10 \\
\hline 7 & No. of labours. & 2 \\
\hline 8 & Wag of labour per day, LE & 50 \\
\hline 9 & Daly working hours & 8 \\
\hline 10 & Yearly operation (H), hours. & 200 \\
\hline
\end{tabular}




\section{RESULTS AND DISCUSSION}

\subsection{Physical properties of the graded fruits:}

The physical properties of the Valencia orange fruits have been measured as one of the important factors affecting on the designing and fabricating the weight grading prototype and also affecting the transporting, handling and exporting operation of these fruits. The physical properties, which have been measured, include length, diameter, shape index, volume, mass and density as shown in Table 3

Table 3: Physical properties for Valencia orange fruit:

\begin{tabular}{|l|c|c|c|c|c|c|}
\hline Items & $\begin{array}{c}\text { Length, } \\
\mathbf{m m}\end{array}$ & $\begin{array}{c}\text { Diameter, } \\
\mathbf{m m}\end{array}$ & $\begin{array}{c}\text { Shape } \\
\text { index }\end{array}$ & $\begin{array}{c}\text { Mass, } \\
\mathbf{g}\end{array}$ & $\begin{array}{c}\text { Volume, } \\
\mathbf{c m}^{\mathbf{3}}\end{array}$ & $\begin{array}{c}\text { Density, } \\
\mathbf{g} / \mathbf{c m}^{\mathbf{3}}\end{array}$ \\
\hline Min. & 51.00 & 52.00 & 0.90 & 83.00 & 90.00 & 0.76 \\
\hline Max. & 80.00 & 76.00 & 1.10 & 260.00 & 190.00 & 1.53 \\
\hline Sum & 6685.00 & 6419.00 & 104.30 & 16376.00 & 133309.00 & 121.74 \\
\hline Av. & 66.8500 & 64.19 & 1.04 & 163.76 & 133.09 & 1.25 \\
\hline S.D. & 6.27 & 5.64 & 0.05 & 40.75 & 21.89 & 0.14 \\
\hline C.V. & 9.40 & 8.79 & 5.18 & 24.88 & 16.45 & 11.67 \\
\hline
\end{tabular}

\subsection{Mechanical properties:}

\subsubsection{Coefficient of friction :}

The suitable surface which gives high value of friction coefficient between the grading machine surface and the tested fruits surface must be determined to satisfy the design requirements. The average values of Coefficient of friction ( $\mu$ ) for Valencia orange fruits have been determined on various surfaces used for the proposed design (wood, cotton, linen and leather). The values of coefficient of friction were 0.17 , $0.24,0.20$ and 0.17 for (wood, cotton, linen and leather) respectively as shown in Fig 4. The results revealed that, the maximum value of friction coefficient was 0.24 which was obtained using the cotton surface. However, minimum value was 0.17 due to using the wood and leather surface. In this study, the surface with highest value of friction coefficient has been used and it was cotton. The chosen surface prevents 
the fruit from sliding over and reduces the damage that may happen due to falling of fruits from feeding unit.

\subsubsection{Rolling angle:}

The rolling angle was an important factor which was used for determining the slope of the inner surface of orange tank in addition to determine the slope of the transport belts. The rolling angles on (wood, cotton, linen and leather) surfaces for Valencia orange fruits have been measured.

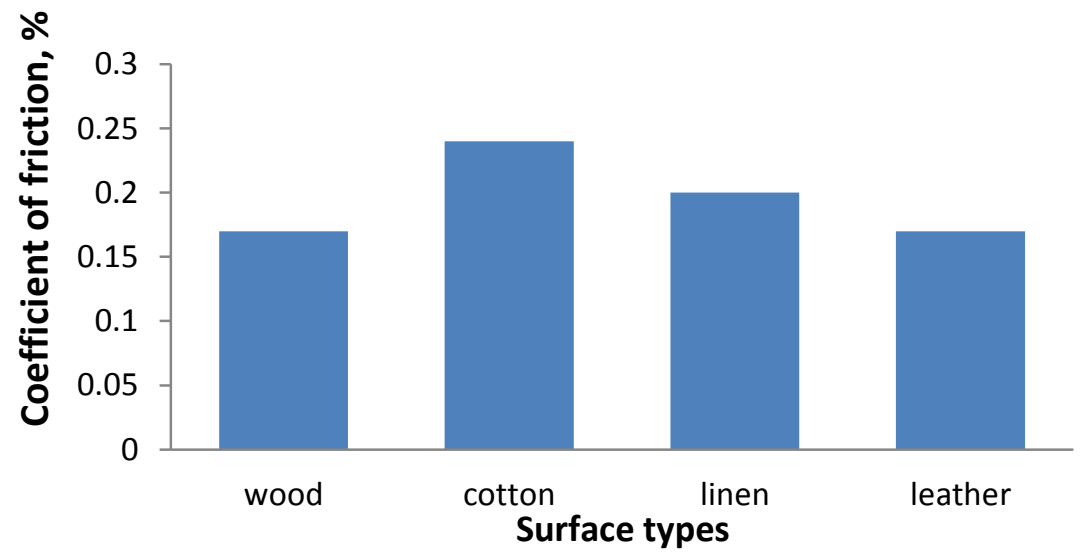

Fig. 4 Coefficient of friction for Valencia orange on wood, cotton, linen and leather

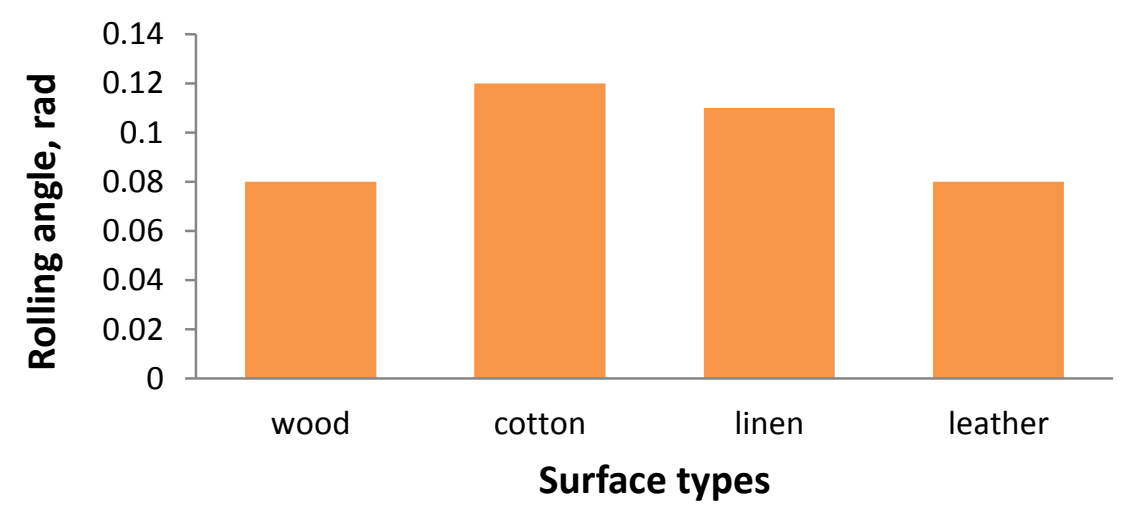

Fig. 5 Rolling angle for Valencia orange on wood, cotton, linen and leather 
The experimental work has been conducted at one position of fruit movement where the small axis of fruit was laid vertical to the direction of motion. The obtained values of rolling angle at (wood, cotton, linen and leather) surfaces were $0.08,0.12,0.11$ and $0.08 \mathrm{rad}$, respectively as shown in Fig.5. It can be noticed that the maximum value of rolling angle was $0.12 \mathrm{rad}$ which was obtained with using the cotton surface. While, the minimum value was $0.08 \mathrm{rad}$ due to using the wood and leather surface.

\subsubsection{Impact height:}

Study of impact heights is important to determine the height, which causes damage to the fruit. The observed result showed that, the maximum impact heights causing damage was $1150 \mathrm{~mm}$ for Valencia orange fruit. The above mentioned results were considered in calculation of the proper dropping height of fruit at different positions of the grading unit. In general, the maximum height used not exceeds $300 \mathrm{~mm}$, as the height of prototype was $1100 \mathrm{~mm}$ and the grading boxes have been put on a distance not exceed $300 \mathrm{~mm}$ from the prototype.

\subsection{Efficiency of grading prototype:}

\subsubsection{Effect of the infrared control unit and the weight sensing time on the grading efficiency:}

The effect of infrared control unit and the weight sensing time on the grading efficiency of the constructed automatic grading prototype has been indicated in Table 4. It can be noticed that increasing weight sensing time from 3 to $9 \mathrm{sec}$ during the grading process tended to decrease the grading efficiency of the automatic grading prototype with non-significant differences due to changing weight sensing time from 97.10 to $94.03 \%$ with using infrared control unit and from 72.89 to 21.20 $\%$ with significant differences between weight sensing time without using infrared control unit.

The significant differences between weight sensing time may be attributed to decrease the accuracy of the weight and increase the overlapping percentage as a result to increase the weight sensing time when grading without using infrared control unit which tends to decrease the efficiency. Also, the weight sensing time of $3 \mathrm{sec}$ with using infrared 
control unit achieved the maximum grading efficiency compared without using infrared control unit, while, the minimum grading efficiency had been obtained without using infrared control unit. Using the automatic control for adjusting weight sensing time and using infrared control unit have been caused non-significant differences due to changing weights sensing time.

Table 4: Effect of the infrared control unit and the weight sensing time on the grading efficiency:

\begin{tabular}{|c|c|c|}
\hline \multirow{2}{*}{$\begin{array}{c}\text { weight sensing } \\
\text { time, sec }\end{array}$} & \multicolumn{2}{|c|}{ Infrared control unit } \\
\cline { 2 - 3 } & $\begin{array}{c}\text { With infrared } \\
\text { control unit }\end{array}$ & $\begin{array}{c}\text { Without infrared } \\
\text { control unit }\end{array}$ \\
\hline $\mathbf{3}$ sec & $97.10 \mathrm{a}$ & $72.89 \mathrm{~b}$ \\
\hline $\mathbf{6}$ sec & $94.50 \mathrm{ab}$ & $46.08 \mathrm{c}$ \\
\hline $\mathbf{9}$ sec & $94.03 \mathrm{ab}$ & $21.20 \mathrm{~d}$ \\
\hline
\end{tabular}

3.3.2 Effect of the infrared control unit and the distances between spoons on the grading efficiency for all weight sensing time:

The data presented in the Table 5 showed that using distance $182 \mathrm{~mm}$ between spoons with infrared control unit and 3 seconds for weight sensing time gave the highest value of efficiency which was $98.5 \%$, while, weight sensing time of 6 and $9 \mathrm{sec}$ gave 97.3 and $94.91 \%$, respectively. Also, using $364 \mathrm{~mm}$ distance between spoons with infrared control unit and weight sensing time of 3,6 and 9 sec gave grading efficiency $95.67 \%, 91.67$ and $92.13 \%$ respectively without significant differences due to changing weight sensing time. On the other hand, using distance $182 \mathrm{~mm}$ between spoons without infrared control unit and 9 seconds for weight sensing time gave the lowest value of efficiency which was $11.67 \%$ with highly significant difference with the other treatments. Compared with early developed Valencia orange mechanical grading machines with maximum efficiency of $91.67 \%$, the current 
prototype can achieve higher grading efficiency if the optimum operating parameters have been adapted.

Table 5: Effect of the infrared control unit and the distances between spoons on the grading efficiency for all weight sensing time:

\begin{tabular}{|c|c|c|c|c|}
\hline \multirow{2}{*}{$\begin{array}{c}\text { Distance } \\
\text { between } \\
\text { spoons, } \\
\text { mm }\end{array}$} & \multirow{2}{*}{ Infrared control unit } & \multicolumn{3}{|c|}{ Grading efficiency, \% } \\
\cline { 3 - 5 } & & \multicolumn{2}{|c|}{ Weight sensing time, sec } \\
\cline { 3 - 5 } & & $\mathbf{3 ~ s e c}$ & $\mathbf{6 ~ s e c}$ & $\mathbf{9}$ sec \\
\hline \multirow{2}{*}{182} & With infrared control unit & $98.53 \mathrm{a}$ & $97.3 \mathrm{ab}$ & $94.91 \mathrm{ab}$ \\
\cline { 3 - 5 } & Without infrared control unit & $67.31 \mathrm{f}$ & $29.56 \mathrm{~g}$ & $11.67 \mathrm{~h}$ \\
\hline \multirow{2}{*}{364} & With infrared control unit & $95.67 \mathrm{ab}$ & $92.13 \mathrm{~b}$ & $91.67 \mathrm{~b}$ \\
\cline { 2 - 5 } & Without infrared control unit & $78.53 \mathrm{c}$ & $62.60 \mathrm{~d}$ & $30.71 \mathrm{e}$ \\
\hline
\end{tabular}

Increasing weight sensing time from 3 to $9 \mathrm{sec}$ with using the distance of $364 \mathrm{~mm}$ between spoons without infrared control unit led to decrease the grading efficiency from 78.53 to $30.71 \%$ respectively. Also, it was observed that using any of the distances between spoons without infrared control unit led to decrease the efficiency of the prototype because the non-stop working of the feeding chain, the fruits were falling from the feeding unit to the sensing area continuously and hence, wrong values of masses were recorded.

\section{4: Productivity of automatic grading prototype:}

The productivity of grading prototype decreased as a result of increasing weight sensing time for the Valencia orange fruits Table 6. Increasing the weight sensing time from 3 to $9 \mathrm{sec}$ tended to decrease the productivity of the automatic grading prototype from 0.47 to $0.17 \mathrm{Mg} / \mathrm{h}$ at $182 \mathrm{~mm}$ distance between spoons and from 0.42 to $0.16 \mathrm{Mg} / \mathrm{h}$ at $364 \mathrm{~mm}$ distance between spoons. Also, it can be noticed that the obtained productivities of grading Valencia orange fruits with using distance $182 \mathrm{~mm}$ between spoons were higher than arranging the spoons at distance of $364 \mathrm{~mm}$, and same trend for or all weight sensing time. From the data presented in the Table 6, the decrease of the productivities with using the distance between spoons $364 \mathrm{~mm}$ may be attributed to the time that the fruits took when the feeding chain moved was more than the time in the case of 182 $\mathrm{mm}$. 
Table 6: Effect of weight sensing time and the distances between spoons on the grading productivity for Valencia orange fruits:

\begin{tabular}{|c|c|c|}
\hline \multirow{2}{*}{$\begin{array}{c}\text { Weight sensing time, } \\
\text { sec }\end{array}$} & \multicolumn{2}{|c|}{$\begin{array}{c}\text { Grading productivity, Mg/h (ton/h) } \\
\text { mistance between spoons, } \\
\text { mm }\end{array}$} \\
\cline { 2 - 3 } & $\mathbf{1 8 2}$ & $\mathbf{3 6 4}$ \\
\hline $\mathbf{3}$ & 0.47 & 0.42 \\
\hline $\mathbf{6}$ & 0.24 & 0.22 \\
\hline $\mathbf{9}$ & 0.17 & 0.16 \\
\hline
\end{tabular}

\subsection{Power unit required for grading operation:}

The power required for operating the automatic grading prototype had been consumed for driving conveyer belt and feeding unit chain, fruit weighting, grading gates movements and controlling the electronic circuits as listed in Table 7. The power consumed for grading prototype operation were $0.039,0.024$ and $0.019 \mathrm{KW}$ at the weight sensing time 3 , 6 and $9 \mathrm{sec}$, respectively. The data listed in Table 8 presents the calculated power and energy consumed for operating the automatic grading prototype as affected by the different weight sensing time. Also, it can be noticed that the energy consumed of grading the Valencia orange fruits with using the weight sensing time of $3 \mathrm{sec}$ less than the energy consumed when using the weight sensing time of $9 \mathrm{sec}$ as were 0.083 and $0.112 \mathrm{KW} . \mathrm{h} / \mathrm{Mg}$ respectively, This resulted may be attributed to decrease productivity from 0.47 to 0.17 when the weight sensing time increased from 3 to $9 \mathrm{sec}$. With such required energy, the current prototype consumes energy less than similar developed machines for grading orange.

Table 7: The power consumed during grading Valencia orange fruits for each part.

\begin{tabular}{|l|c|}
\hline \multicolumn{1}{|c|}{ Item } & The power consumed, $\mathbf{k W}$ \\
\hline Eclectic motor ( main motor) & 0.024 \\
\hline Gate motor & 0.002 \\
\hline Arduino & 0.001 \\
\hline Infrared control unit & 0.0036 \\
\hline
\end{tabular}

*Power factor $=\mathbf{1 0 / 8}$ 
Table 8: The power and energy consumed during grading Valencia orange fruits.

\begin{tabular}{|c|c|c|}
\hline $\begin{array}{c}\text { Weight sensing } \\
\text { time, sec }\end{array}$ & $\begin{array}{c}\text { The power } \\
\text { consumed, } \\
\mathbf{k W}\end{array}$ & $\begin{array}{c}\text { The energy } \\
\text { consumed, } \\
\mathbf{k W} . \mathbf{h} / \mathbf{M g}\end{array}$ \\
\hline $\mathbf{3}$ & 0.039 & 0.083 \\
\hline $\mathbf{6}$ & 0.024 & 0.10 \\
\hline $\mathbf{9}$ & 0.019 & 0.112 \\
\hline
\end{tabular}

\subsection{Cost analysis:}

The cost evaluation for the grading prototype done at the recommended suitable operating parameters of $3 \mathrm{sec}$ as weight sensing time and 182 $\mathrm{mm}$ distance between spoons. The results indicated that the discrete components of cost were $9 \mathrm{LE} / \mathrm{h}$ for the fixed cost and $17 \mathrm{LE} / \mathrm{h}$ for the variable cost. However, the total costs required for grading operation were $26 \mathrm{LE} / \mathrm{h}$ and weight unit cost of grading Valencia orange using the automatic grading prototype was $55 \mathrm{LE} / \mathrm{Mg}$. Cost evaluation of the grading machine was obtained in Table 9.

\section{Table 9: Cost evaluation for the grading machine}

\begin{tabular}{|c|l|c|}
\hline No. & \multicolumn{1}{|c|}{ Cost items } & Cost \\
\hline 1 & Machine price, L.E costs of materials and fabrications ( P ), LE & 10000 \\
\hline \multirow{3}{*}{2} & Fixed cost: & \\
& Depreciation, L.E / year & 900 \\
& Interest on investment, L.E / year & 675 \\
& Housing and insurance, L.E / year & 200 \\
\hline \multirow{2}{*}{3} & Total fixed cost, L.E / year & 1775 \\
& Total fixed costs, L.E / h & 9 \\
\hline \multirow{3}{*}{3} & Variable costs & \\
& Repair and maintenance, L.E / h & 4.5 \\
& Electric cost, L.E / h & 0.0164 \\
& Labor cost, L.E / h & 12.5 \\
\hline & Total variable costs, L.E / h & 17 \\
\hline 4 & Total costs, L.E / h & 26 \\
\hline \multirow{2}{*}{5} & Total costs for Valencia orange, L.E / Mg & 55 \\
\hline
\end{tabular}

* One American dollar $\cong 18$ Egyptian pound (LE) according to prices 2016. 


\section{CONCLUSION}

The results showed that development of such prototype is considering adoptive research at any institution or industry whose practices are based on electronic engineering systems for grading and sorting. The research findings from current study are to guide the industrial stakeholders and processors to easier and faster way for grading and packaging their products. The automatic grading machine can obviously reduce the costs of grading operation than the manual grading. The optimum operational conditions for grading Valencia orange fruits, which achieved maximum grading efficiency and productivity, were using the automatic grading prototype at $182 \mathrm{~mm}$ distance between spoons, and limiting weight sensing time to $3 \mathrm{sec}$ and to use infrared control unit. In this study, the grading efficiency has been increased when the distance between spoons decreased for all the weight sensing time and using infrared control unit. With decreasing weight sensing time, grading efficiency has been increased. The power unit consumed for driving and operating the automatic grading prototype increased when the weight sensing time decreased, and the required energy consumed was $0.083 \mathrm{~kW} . \mathrm{h} / \mathrm{Mg}$ with the optimum operational conditions. The total cost of Valencia orange fruits automatic grading system was $55 \mathrm{LE} / \mathrm{Mg}$, which makes the prototype in a comparative manner with low processing machines

\section{REFERENCES}

Abd El-Mageed, H. N. and H. E. Abd-Alla (1994). A simple machine for grading fresh tomatoes. J. Agric. Sci., Mansoura Univ., 19 (9): $3033-3047$.

Amer Eissa, A. H. and A. A. Abdel Khalik (2012). Understanding color image processing by machine vision for biological materials. In: Structure and Function of Food Engineering (Ed: Ayman Amer Eissa), ISBN 978-953-51-0695-1, InTech Publisher, p: 414. 
Amin, E. A. (1994). Development of grading machine for some Egyptian farm crops. J. Agric. Sci., Mansoura Univ., 19 (7): 2398 - 2411.

Anon. 2002. Proposal to revise Economic Commission for Europe Standards, Committee for trade, industry and enterprise development. Working Party on Standardization of Perishable Produce and Quality Development Specialized Section on Standardization of Fresh Fruit and Vegetables. Forty-eighth session, 23-26 April, Geneva.

Brennan, J. G. and A. S. Grandison (2006). Food Processing Handbook. Chapter 1: Postharvest Handling and Preparation of Foods for Processing. WILEY-VCH Verlag GmbH \& Co. KGaA. Weinheim. United Kingdom. P: 1-30.

El-Khawaga, S. E. (1999). Developing of a harvesting machine for some fruit crops. Unpublished Ph. D. Thesis, Agric. Mech. Dept., Fac of Agric., Mansoura. Univ.

Gomaa, S. M., H. M. H. Sorour, O.M. Kamel, and E.M. Ghazy (2006). Utilization of Electronic Circuits to Operate a Grading Prototype Machine for Some Fruits and Vegetables on Weight Base. Misr J. Ag. Eng., 23(1), p: 192 - 216.

Jarimopas, B., S. Toomsaengtong, S.P. Singh, J. Singh and R. Sothornvit (2007). Development of wholesale packaging to prevent post-harvest damage to rose apples. J. Appl. Packaging Res. 2(1), p: 27- 44.

Kondo, N. (2009). Automation on fruit and vegetable grading system and food traceability. Trends in Food Science and Technology 21 (3),p: 145-152. 
Mangraj, S., Singh K. K., Varshney, A. C.; ans B. S. Redd (2009).

Design and development of fruit grader. J. Food Sci.Technol., 46 (6), 554-558.

Mcrae, D. C. (1985). A review of developments of potato handling and grading. J. Agric. Eng. Res., 31: 115-138.

Omre, P. K, R. P. Saxena (2003). Design and development of multifruit grader. Agric. Mech. Asia, Africa Latin Am‘. 34(4), p: 39-42, 52.

Ryall, A. L., D. J. Lipton (1972). Handling, Transportation and Storage of Fruits and Vegetables. $2^{\text {nd }}$ Ed., AVI. Pub. Co. Inc, West port, Connecticut, USA.

Peleg, K. (1985). Produce Handling, Packaging and Distribution. Connecticut, USA: AVI. Pub. Co. Inc، Connecticut, USA. P: 91103.

Peleg, K. and Y. Ramraz (1975). Optimal sizing of citrus fruit. Trans. ASAE, 18(6), p: 1035-1039.

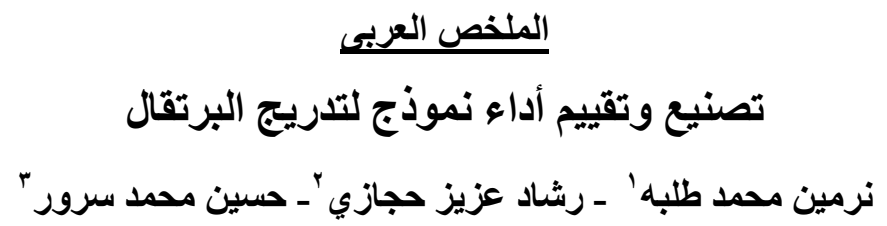

تعتبر عملية التدريج من أهم عمليات تداول المنتج الزر اعى بعد عملية الحصاد، حيث تؤدى الى الى رفع جودة المنتج النهائى" سواء للاستهلاك المحلى أو للتصدير . تدريج المنتج يتم إلى عدة فئات التهات

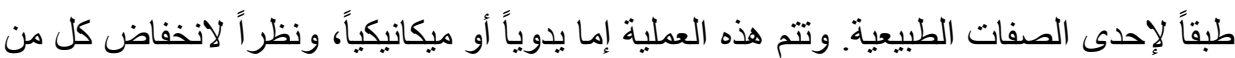
سعة وكفاءة التدريج اليدوى وارتفاع تكلفته وتعرض الثمار للتلوث، يفضل إجر اء عملية التدريج

1 باحث مساعد- معهد بحوث الهندسه الزراعية ــ مركز البحوث الزراعية ــ الدقي- الجيزه.

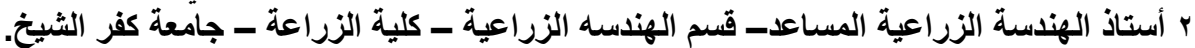

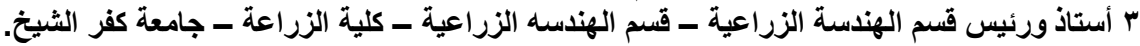


بالطرق الميكانيكية. وقد أدى قصور آلات التدريج الحجمى فى تدريج اكثر من محصول الى الى الكي

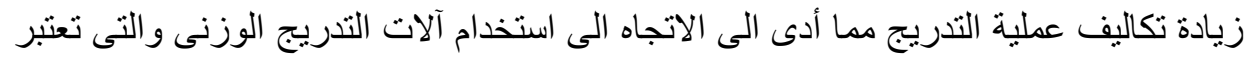

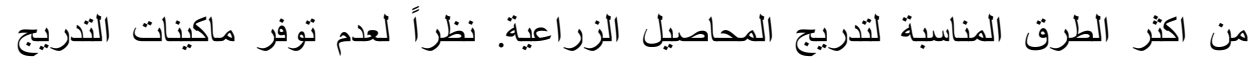

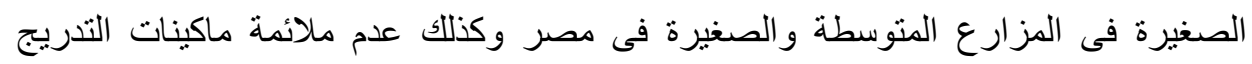

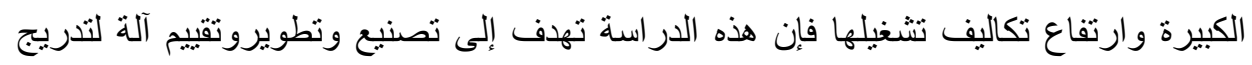

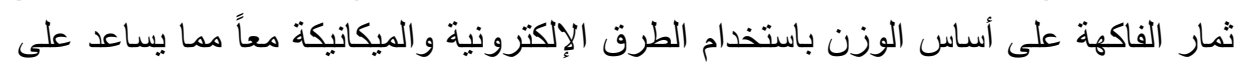

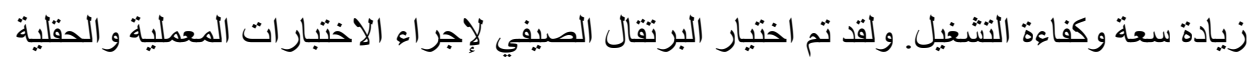

على الآلة.

اشتملت الألة المصنعة كنموذج أولي علي وحدتين اساسيتين هما وحدة التغذية ووحدة التنريج.

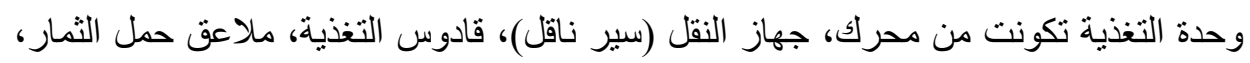

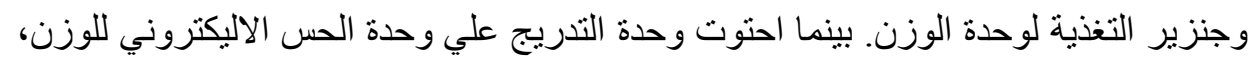

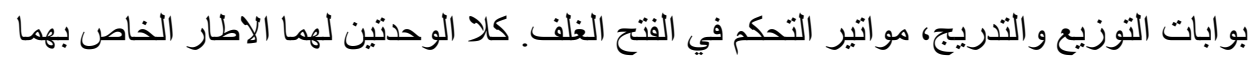

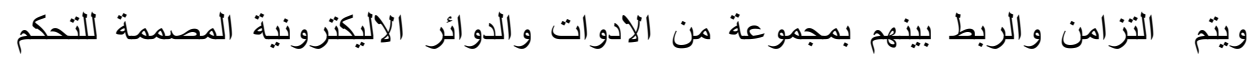
وضمان ربط وتحسين الاداء للنموذج المصنع.

تم تصنيع النموذج محل الدراسة والدوائر الاليكترونية والاجهزة الميكانيكية المستخدمة في

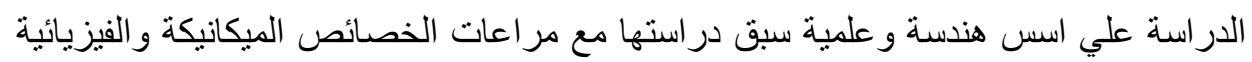

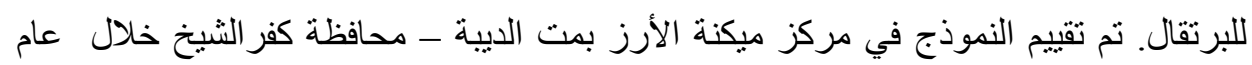

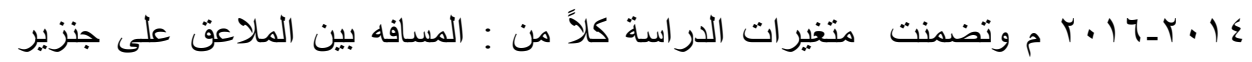

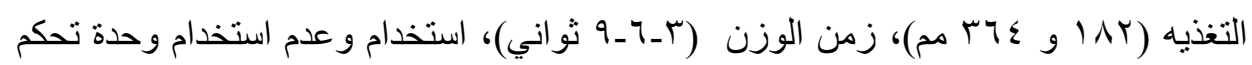

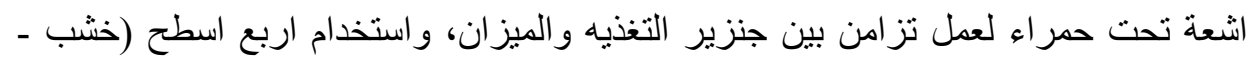

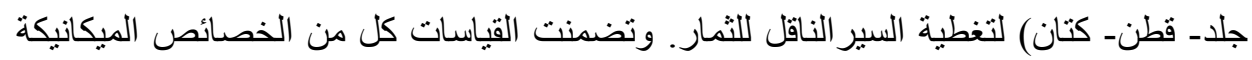

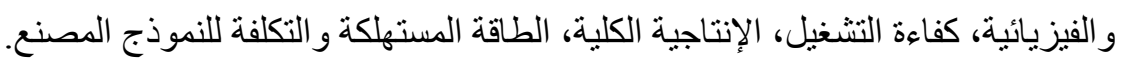

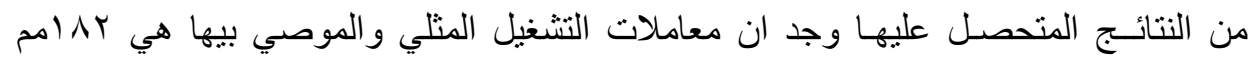

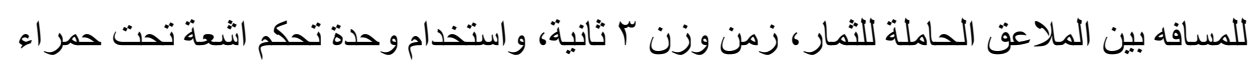

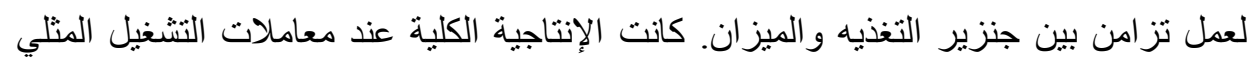

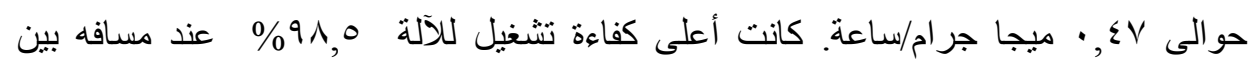

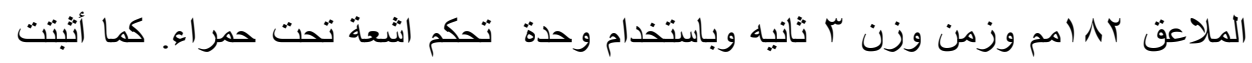

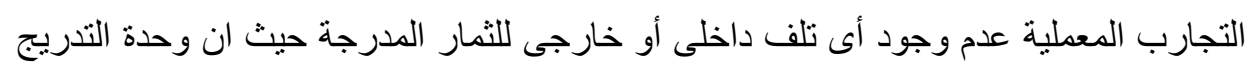

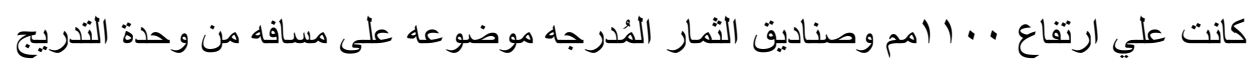


لاتزيد عن .r مم. أوضحت الدراسة أن حسابات الطاقة المستهلكة عند معاملات التشغيل

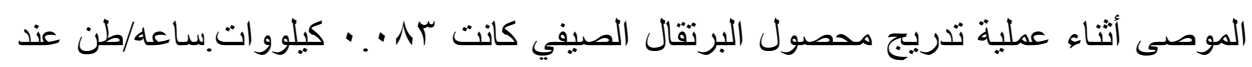

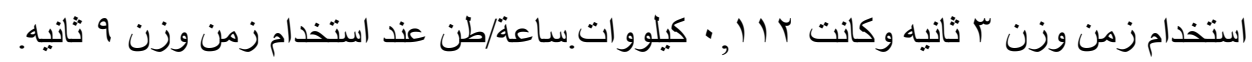

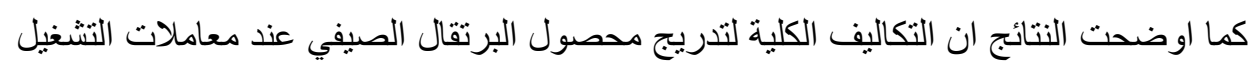
الموصى بها كانت 00 جنيه / طن. 